\title{
Regionale sykelighetsforskjeller i Nord-Trøndelag fylke belyst ved tall fra ulike datakilder
}

\author{
Steinar Fretland og Øystein Krüger \\ Samfunnsmedisinsk forskningssenter, Neptunveien 1, 7650 Verdal \\ Telefon $74075180 \quad$ Telefax 74075181 e-post sfretlan@online.no
}

\begin{abstract}
SAMMENDRAG
Nord-Trøndelag fylke inndeles i to sykehusområder, Namdal i nord/nordvest og Innherred i sør. Det er tidligere påvist høyere sykehusforbruk i Namdal enn i Innherred. En undersøkelse fra 80-tallet tydet på at forhold i primærhelsetjenesten forklarte noen av disse forskjellene: større stabilitet blant primærlegene og bedre samarbeid mellom første- og andrelinjetjenesten i Innherred kunne forklare lavere sykehusforbruk i dette området. Forhold knyttet til geografi, næringsstruktur og befolkningssammensetning så ikke ut til å spille noen vesentlig rolle. Formålet med denne undersøkelsen var å kartlegge eventuelle forskjeller i sykelighet mellom befolkningene i Namdal og Innherred. For å beskrive sykdomsmønstre i fylket har vi hentet data fra befolkningsundersøkelser i fylket, fra sykehusstatistikk, fra registrering hos primærleger, fra kreftregisteret, fra meldingssystemet for infeksjonssykdommer, fra dødsårsaksregisteret, fra fylkets trygdekontor og fra Fylkeslegen. Det var høyere forekomst av hjertesykdom og høyere nivåer for risikofaktorer for hjertesykdom (målte gjennomsnittlige kolesterolverdier, høyt blodtrykk, daglig røyking og infarktrisk-skåre) i Namdal enn i Innherred. Regionale ulikheter i sykelighet registrert ved Helseundersøkelsen i Nord-Trøndelag (HUNT) ble bekreftet av tilsvarende forskjeller ved innleggelser i sykehus for en rekke sykdommer.
\end{abstract}

Fretland S, Krüger Ø. Regional differences in disease morbidity in Nord-Trøndelag county. Nor J Epidemiol 1998; 8 (1): 73-78.

\section{ENGLISH SUMMARY}

Previous research has revealed that the population-adjusted number of hospital admissions through many years has been higher in Namdal than in Innherred hospital region. This was not explained by differences in population age or sex distributions, but was to some extent associated with the level of primary health care. The aim of this study was to investigate if there were differences in morbidity between the two hospital regions. We have used different sources to collect information about the disease patterns: The NordTrøndelag Health Survey, data from general practitioners in the county, the Cancer Registry of Norway, the National Institute of Public Health, the hospital registers in the county of Nord-Trøndelag, the National Death Register, the public insurance company and from the County Health Office. There was a substantially higher occurrence of heart disease and risk factors for heart disease (levels of cholesterol and blood pressure, cigarette smoking and infarction risk score) in Namdal than in Innherred hospital region. The regional differences in coronary heart disease were clearly confirmed in hospital admission data, and also for several other diseases: stroke, asthma, rheumatoid arthritis, Bechterew's disease and arm and hip fractures - the direction of the regional differences were similar in the health survey and in the hospital admission data.

\section{INNLEDNING}

Det er gjennom flere år påvist ulik bruk av de to sykehusene i Nord-Trøndelag, idet antall innleggelser per innbygger er høyere i Namdal enn i Innherred sykehusområde (1-5). Selv etter korreksjon for aldersog kjønnssammensetning, holder forskjellene seg. Ulik kapasitet og tilgjengelighet av sykehustjenester er sannsynligvis en forklaring. Videre kan forskjeller mellom sykehusene i forholdet mellom behandling ved innleggelse kontra ved poliklinikk virke inn. Thorsvik fant i 1986 at faktorer i primærhelsetjenesten delvis kunne forklare ulik bruk av sykehusene; det var bl.a. mer stabil primærlegetjeneste og bedre samarbeid mellom første og andre linje i Innherred enn i Namdal sykehusområde (1). Norsk institutt for sykehusforskning har funnet at forskjeller knyttet til geografi, næringsstruktur og befolkningssammensetning ikke spilte noen vesentlig rolle for regionalt forskjellig sykehusbruk målt i innleggelser i Nord-Trøndelag $(1,2)$. 
Alle årsaker til det høyere sykehusbruk i Namdal enn i Innherred er ikke klarlagt. Vi har i denne undersøkelsen fokusert på mulige sykelighetsforskjeller. Gjennom ulike kilder har vi belyst en del sykdommers utbredelse og sammenlignet befolkningene i Namdal og Innherred. Spesielt har vi hatt god tilgang på bakgrunnsmateriale fra Helseundersøkelsen i NordTrøndelag (HUNT) og fra sykehusstatistikk i fylket og vi har kunnet vurdere evt. samsvar i funn mellom disse to datakildene.

\section{MATERIALE OG METODE}

\section{Fylket-beskrivelse}

Nord-Trøndelag består av 24 kommuner med til sammen 127300 innbyggere (1.1.96). Fylket har en todeling av ansvaret for sykehustjenester. Innherred sykehusområde omfatter den sørlige delen av fylket - i alt 10 kommuner og 87000 innbyggere. Namdal sykehusområde (43800 innbyggere) består av de 14 kommunene nord i fylket samt Bindal i Nordland og Osen i Sør-Trøndelag. Sju av kommunene i Namdal har kystlinje mot Norskehavet. Bosetningen i NordTrøndelag er konsentrert i kommunene langs aksen Stjørdal-Namsos.

Det har de seneste tiårene skjedd en utflytting fra utkantkommunene til disse sentrale kommunene, og dels ut av fylket. I 1970 var $36 \%$ av fylkets befolkning bosatt i tettsteder med mer enn 200 innbyggere mens denne andelen i 1990 var øket til 52\% (6). Det er først og fremst de unge kvinnene som reiser fra distriktene og spesielt rammes kommunene nord i fylket (7). Andelen eldre over 67 år er 15,1\% og har øket jevnt de siste 20 år - samtidig som andelen av barn under 7 år har gått ned (8). For Namdalskommunene samlet er andelen eldre (over 67 år) 16,3\% og for kommunene i Innherred sykehusområde 14,5\%.

I Namdalen er det gradvis overgang fra kyst mot innlandsklima fra vest mot øst, og mye nedbør vest for fjellene i indre Namdal. Innherredskommunene er delvis skjermet for store nedbørsmengder fra kysten og har temperaturnormaler tilnærmet et innlandsklima. Næringsstrukturen i fylket som helhet er preget av primærnæringer, men det er store variasjoner mellom kommunene.

\section{Datakilder}

Sykdomspanoramaet i en befolkning vil se svært ulikt ut - avhengig av hvor informasjonen kommer fra $(9$, 10). F.eks. er det muskel-skjelett og psykiske lidelser som dominerer i trygdestatistikken mens sykdommer i hjerte- og karsystemet og kreft er viktigste dødsårsaker i dødelighetsregisteret. I denne undersøkelsen har vi brukt data fra Helseundersøkelsen i Nord-Trøndelag (HUNT), diagnoseregistrene ved sykehusene, primærlegene, Kreftregisteret, Meldesystemet for infeksjonssykdommer, Statistisk sentralbyrå, dødsårsaksregisteret, trygdestatistikk og Fylkeslegens registreringer.
Tallene fra sykehusene er forste gangs innleggelse for den aktuelle sykdom i perioden 1988-1997. Insidensen ville blitt falskt for høy dersom alle innleggelser ble tatt med fordi mange pasienter blir lagt inn under samme diagnose når de kommer for f.eks. fjerning av osteosyntesemateriale, til rehabilitering eller pga. forverring i forløpet av samme sykdom. De første par årene er likevel insidensen noe for høy fordi noen innleggelser er reinnleggelser fra før 1988.

Aldersstandardisering er gjort ved direkte metode og med befolkningen i fylket per 1.1.1992, ti-års aldersgruppert, som grunnlag for sykehusregistrert sykelighet og ved indirekte metode i standardiseringen av HUNT-tall.

\section{RESULTATER}

Både tall fra HUNT (figur 1) og innleggelsestall i sykehusene (figur 2) tyder på høyere hyppighet av hjerteinfarkt i Namdal enn i Innherred. En egen prospektiv undersøkelse fra våren 1995 (11), diagnoseregistrering hos primærlegene, trygdedata og dødsårsaksstatistikken for hjerte- karsykdommer pekte i samme retning. Det var også flere som ble innlagt for angina pectoris i Namdal enn i Innherred sykehusområde i perioden 1988-97 og større andel av befolkningen i Namdal enn i Innherred som rapporterte å ha gjennomgått hjerteinfarkt eller ha angina pectoris ved HUNT i 1984-86 og 1995-97. De relative forskjellene mellom Namdal og Innherred var sammenlignbare i HUNT-data og innleggelsesdata fra sykehusene.

Insidens av prostatakreft var $21 \%$ høyere i Namdal og $2 \%$ lavere i Innherred enn forventet i forhold til landsgjennomsnittet. Ved Helseunders $ø$ kelsen i 199597 var det flere fra Namdal enn fra Innherred som svarte at de hadde stoffskiftesykdommer - både hypo$(+25 \%)$ og hypertyreose $(+27 \%)$. Blant menn var det $20 \%$ flere som svarte at de hadde astma i Namdal enn i Innherred og det var også signifikant flere menn innlagt for kronisk obstruktiv lungesykdom i Namdal $(+15 \%)$ mens en for kvinner ikke så slik forskjell. Også for muskel- skjelettlidelsene leddgikt $(+30 \%)$, Bechterews sykdom $(+181 \%)$ og fibromyalgi $(+21 \%)$ registrerte vi høyere forekomst i norddelen av fylket enn i sørdelen ved HUNT 1995-97. Det var imidlertid ikke signifikant forskjell i innleggelsestall for leddgikt. Innherred hadde $6 \%$ høyere insidens av brudd $\mathrm{i}$ håndledd/underarm $(\mathrm{p}<0,05)$.

For psykisk sykdom, kreft (unntatt prostatakreft), hjerneslag, sukkersyke, lårhalsbrudd, multippel sklerose og infeksjonssykdommer fant vi ikke signifikant forskjell i sykelighet mellom de to sykehusområdene.

For en del sykdommer har vi tall både for egenrapportert sykdom ved Helseundersøkelsen i NordTrøndelag 1995-97 og for første gangs innleggelser i sykehusene i perioden 1988-97. I helseundersøkelsen er sykelighetsmålet prosent ja-svar på ulike sykdomsspørsmål og i sykehusstatistikken er det årlig antall innleggelser per 100000 innbyggere. Forskjellen i sy- 


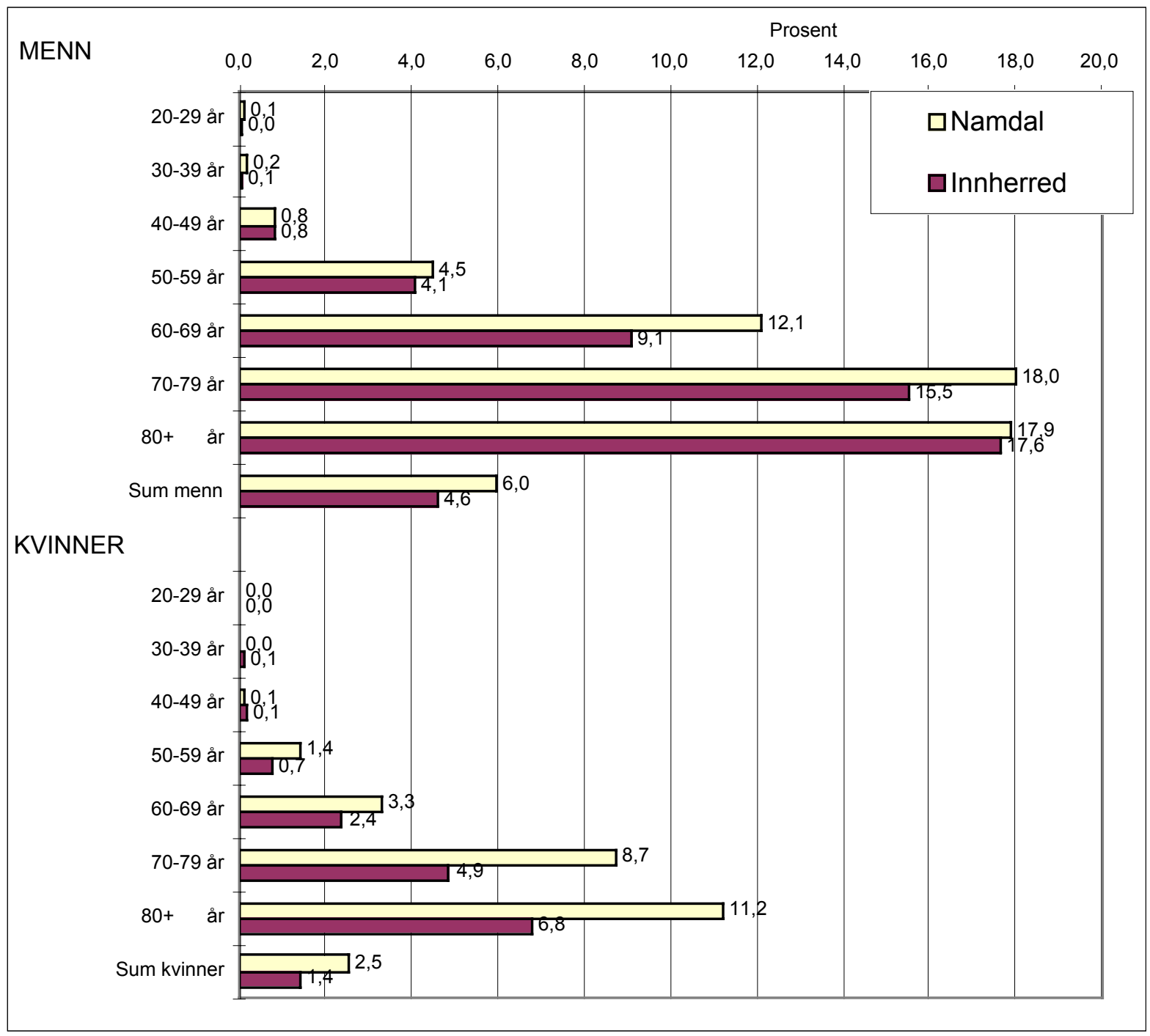

Figur 1. Ja-svar (\%), aldersgruppert, for spørsmålet: "Har du, eller har du hatt hjerteinfarkt?" HUNT 1995-97.

kelighet mellom befolkningene i Namdal og Innherred sykehusområde har entydig samme retning for sykdommene hjerteinfarkt, angina pectoris, hjerneslag, astma, leddgikt, Bechterews sykdom, underarms- og lårhalsbrudd i HUNT data og i sykehusstatistikken (figur 3).

\section{Risikofaktorer}

For hjerte-karsykdommer har vi gjennom Helseundersøkelsen data for noen av de kjente risikofaktorer. Figur 4 viser at det $\mathrm{i}$ alle aldersgrupper og for begge kjønn er høyere gjennomsnittlig målte kolesterolverdier i Namdal enn i Innherred sykehusområde. Kolesterolnivåene avspeiler i stor grad befolkningens kosthold, men matvaner er vanskelig å kartlegge detaljert i befolkningsgrupper. En undersøkelse fra meieridistriktene i Midt-Norge viste at sentrale områder tidligere enn perifere kommuner la om fra fete til magre melketyper (12). Det kan være grunn til å tro at dette er et bevisst valg gjort av den enkelte ut fra ønsket om å leve sunt - og at denne tendensen kan avspeile et "riktigere" forbruk også av andre næringsmidler sett i et forebyggende, helsemessig perspektiv. Melkefettreduksjonen kan således være en indikator på at folk i sentrale, bymessige strøk er tidligere ute enn befolkningen på landsbygda og ved kysten til å legge om til en hjerte-sunn livsstil. Det var signifikant høyere blodtrykk, høyere antall dagligrøykere og høyere infarktrisk (sammenstilling av faktorene kolesterol, systolisk blodtrykk, røyking, familiebelastning med hjerte- karsykdom og kjønn til en skåre) i Namdal enn i Innherred. Gjennomsnittlig målt body mass index (BMI) var ikke signifikant forskjellig i de to sykehusområdene.

\section{DISKUSJON}

Denne undersøkelsen var lagt opp for å beskrive forskjeller i sykelighet mellom to sykehusområder i samme fylke. Hensikten var ikke å avdekke årsaker til 


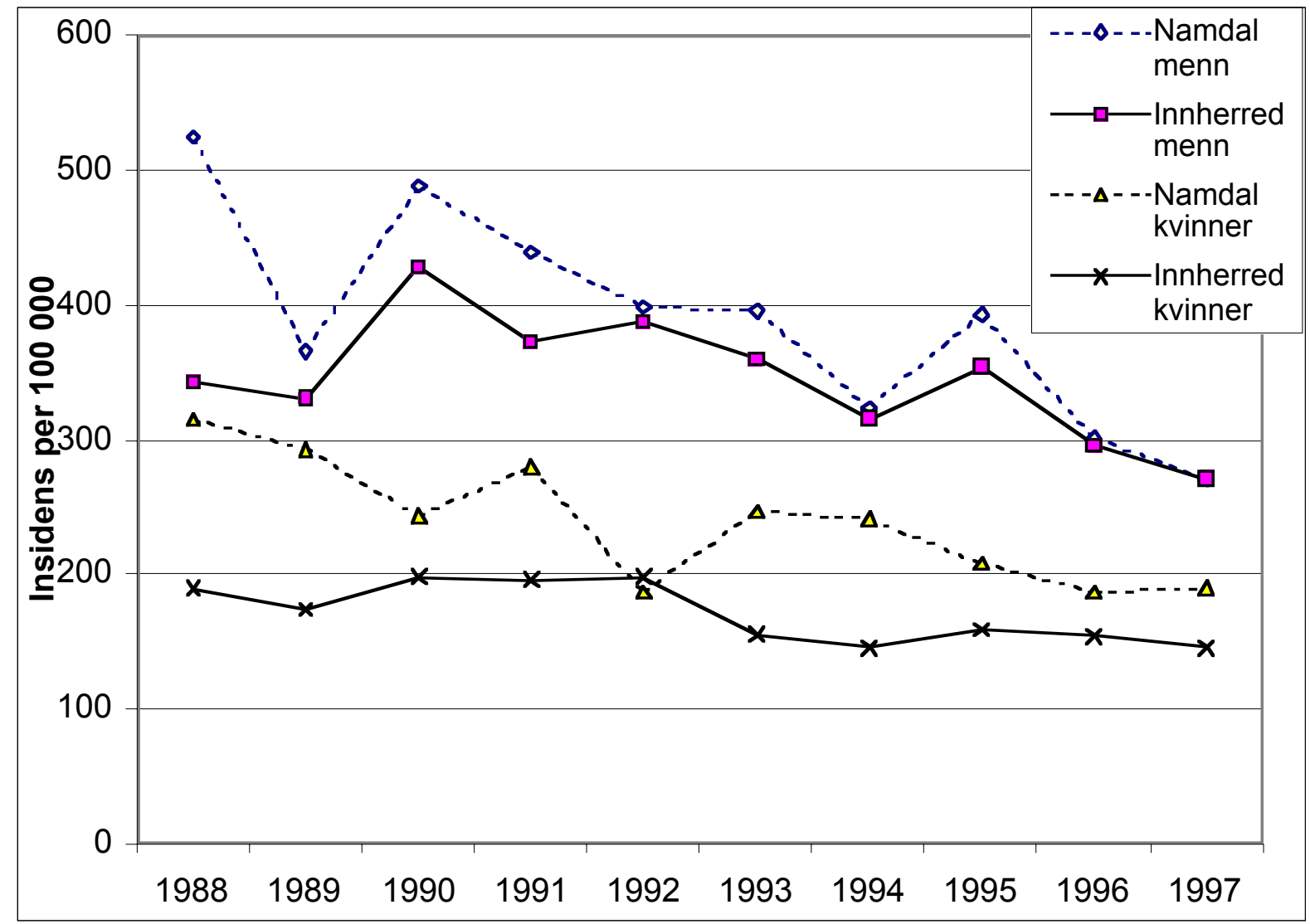

Figur 2. Førstegangsinnleggelser for hjerteinfarkt ved Namdal og Innherred sykehus - årlig insidens per 100000 , aldersstandardiserte tall.

forskjeller i sykelighet. Sykeligheten gir oss et bilde av risiko i fortiden, mens registrerte risikofaktorer ved HUNT 1995-97 peker fremover. Fra 1990 til 1997 var det $\mathrm{i}$ fylket $39 \%$ nedgang i insidens av hjerteinfarkt for menn og $25 \%$ for kvinner. Selv om hyppigheten av hjerteinfarkt er avtagende og forskjellen mellom sykehusregionene blir mindre, spesielt for menn (figur 2), tyder de målte kolesterolnivåer på at Namdal fortsatt vil ha høyere risiko for hjertesykdom de nærmeste årene.

Feilkilder i registreringen av hjerteinfarkt ved sykehusene kan være mulig "lekkasje" av pasienter til andre sykehusområder, ulik avstand til sykehus, behandling av pasienter i kommunene og ulike diagnosekriterier. Ved Innherred sykehus har en satt noe høyere diagnostisk terskel for enzymet kreatin kinase (CK) enn ved Namdal sykehus (13). Imidlertid har vi ikke grunn til å anta at noen av de anførte feilkilder kan rokke ved den registrerte forskjellen i hyppighet av hjerteinfarkt mellom befolkningene i Namdal og Innherred.

Det er langt høyere registrert forekomst av Bechterews sykdom i Namdal enn i Innherred. Tallene for sykehusinnleggelse kan avspeile ulike behandlingsmetoder ved de reumatologiske avdelingene. Ved
Helseundersøkelsen i Nord-Trøndelag 1995-97 var det $3,1 \%$ av befolkningen over 20 år i Namdal og 1,1\% i Innherred som svarte ja på spørsmålet: "Har lege noen gang sagt at du har/har hatt Bechterews sykdom?". Den høyere prevalens i Namdal kan skyldes ulik diagnosesetting i de to sykehusområdene. Vi vet at computertomografi (CT) i stor grad brukes ved Namdal sykehus for å avsløre mulige tidlige forandringer i iliosakralleddene hos pasienter der mistanke om Bechterews sykdom foreligger.

Hvorfor det er ulik forekomst av egenrapportert stoffskiftesykdom, astma hos menn, prostatakreft og brudd i underarm/håndledd er det vanskelig å gi en sikker forklaring på. I kjølvannet av HUNT 1995-97 er det satt i gang prosjekter som ved hjelp av foretatte målinger skal kartlegge utbredelsen av bl.a. stoffskiftesykdom og astma i fylket.

\section{Samsvarende funn fra to datakilder}

Figur 3 viser at for en rekke sykdommer bekreftes de regionale ulikheter observert i befolkningsundersøkelsen ved tallene for sykehusinnleggelser. Begge datakilder inneholder mulige feilkilder. I befolkningsundersøkelser er det avgjørende med godt frammøte, spørsmålsstillingen må ikke være til å misforstå og feil 


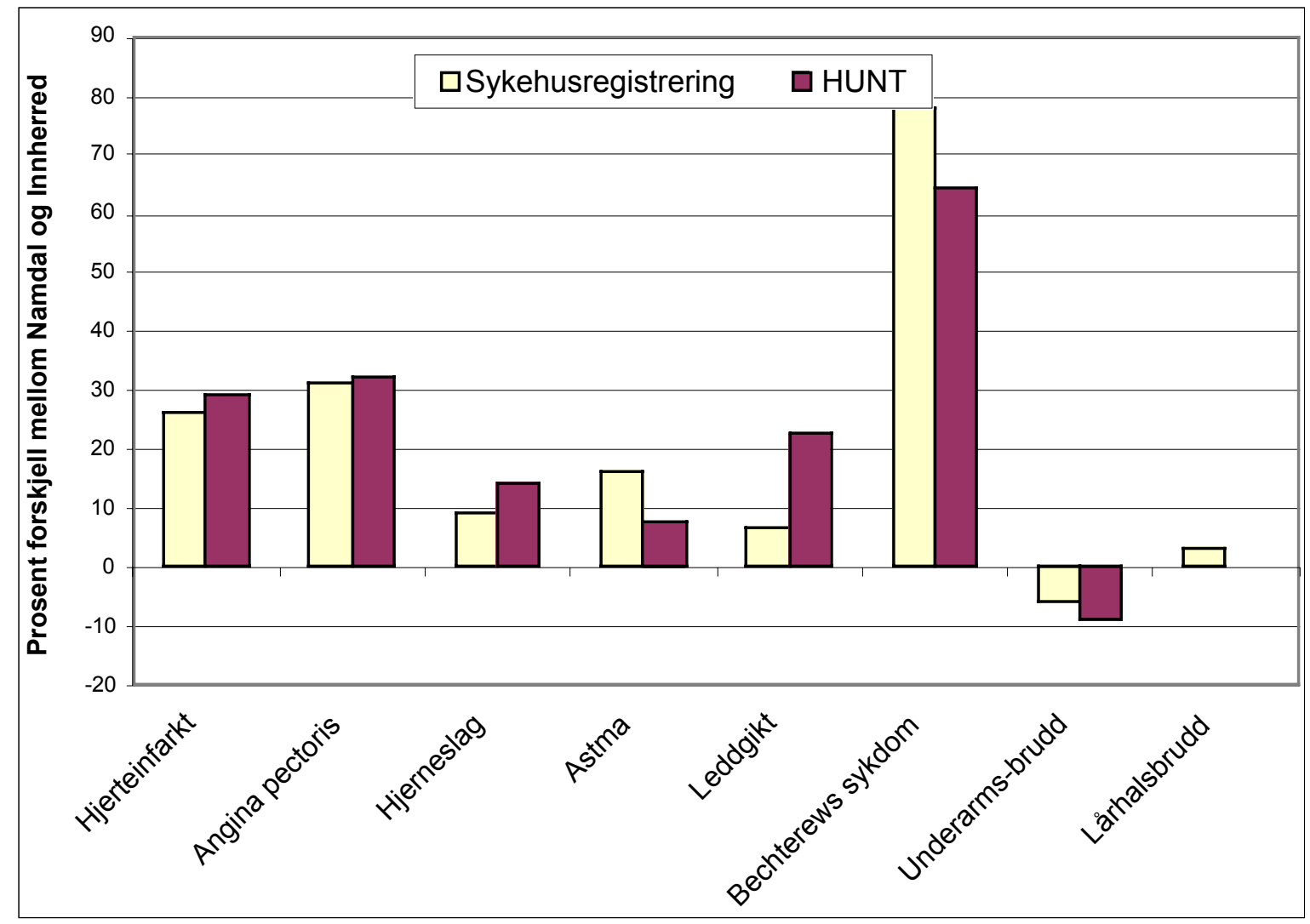

Figur 3. Prosentvis forskjell mellom Namdal og Innherred (Namdal-Innherred) i andel førstegangsinnleggelser på sykehus i perioden 1988-97 og i andel ja-svar for diagnosen ved Helseundersøkelsen i Nord-Trøndelag 1995-97.

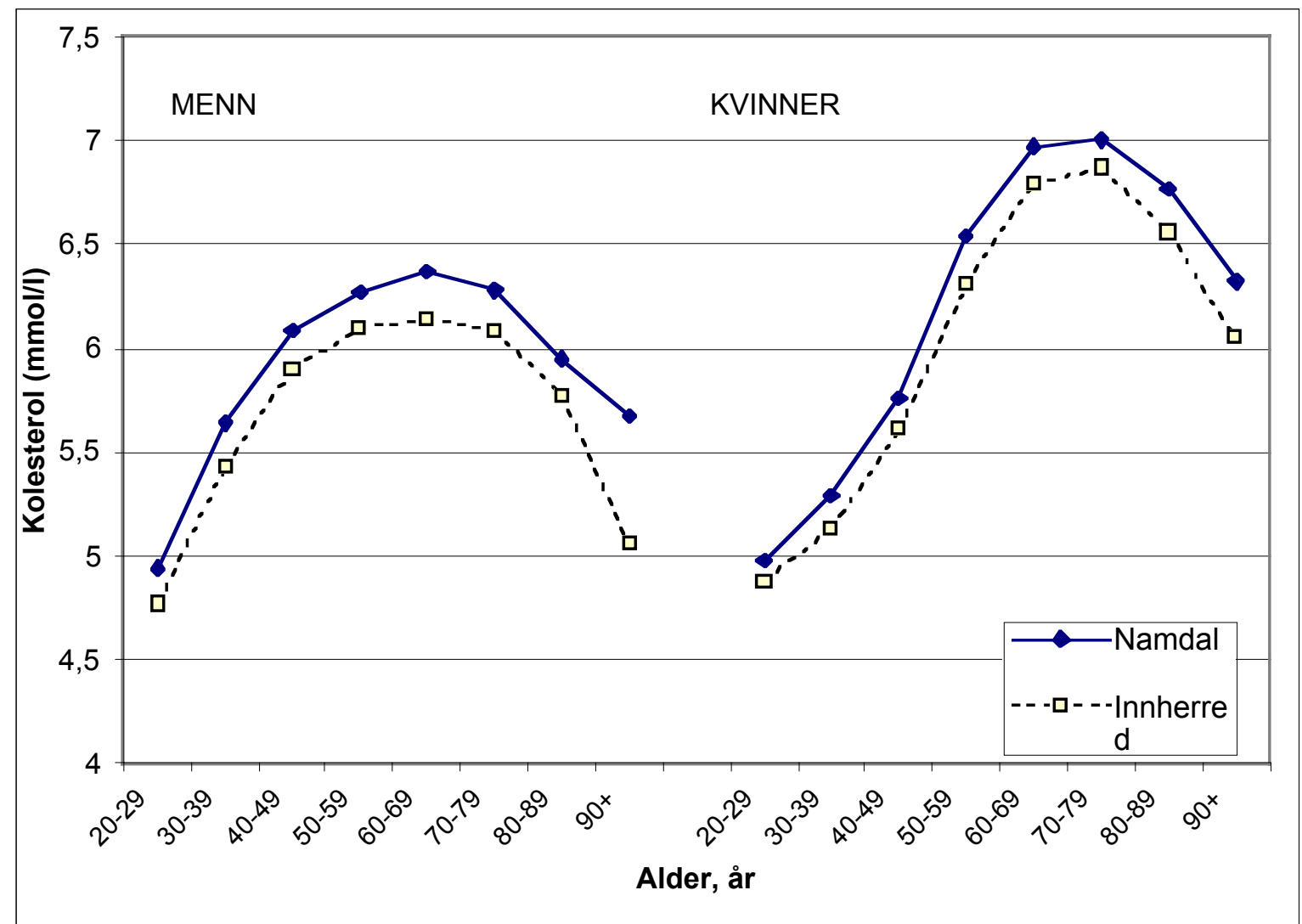

Figur 4. Gjennomsnittlig kolesterol (mmol/l) målt ved HUNT 1995-97. 
kan oppstå dersom respondentens erindring om egen sykehistorie er mangelfull. Ved sammenligning av innleggelsesstatistikk mellom sykehus kan forskjeller i diagnosesetting og behandlingspolitikk influere på resultatet. Den rapporterte sykdom i spørreundersøkelser vil oftest være diagnostisert og behandlet av lege $\mathrm{i}$ sykehus eller i primærhelsetjenesten. I den grad behandling av en sykdom alltid krever sykehusinnleggelse (f.eks. ved hjerteinfarkt, lårhalsbrudd og ved hjerneslag hos yngre) er det ikke urimelig at forskjeller registrert i HUNT og ved innleggelser er overensstemmende. De andre sykdommene som her er tatt med behandles imidlertid dels poliklinisk ved sykehus eller hos primærlege og dels ved innleggelse i sykehus i de alvorligste tilfeller. Terskelen for innleggelse kan variere mellom to sykehusregioner avhengig av en rekke faktorer som f.eks. behandlingsressurser og muligheten for tilsyn og mottak i hjemkommunen. Når to datakilder på denne måten peker i samme retning, styrker dette de konklusjoner som framkommer om likheter og ulikheter i sykdomsmønstre i en region. Tall for sykehusinnleggelser er ved hjelp av Edb-registrering lett tilgjengelige mens gjennomføring av spørreundersøkelser i befolkningsgrupper krever store ressurser. Denne undersøkelsen tyder på at sykehusstatistikk gir et noenlunde riktig bilde av regionale sykelighetsforskjeller innen et fylke når sykehusenes ansvarsområder er klart avgrenset som i Nord-Trøndelag.

\section{REFERANSER}

1. Thorsvik D. Primærhelsetjenesten og sykehusforbruket. En analyse av forskjellene i forbruk av sykehustjenester i Nord-Trøndelag. Verdal: Statens institutt for folkehekse, gruppe for helsetjenesteforskning, distriktskontoret i Verdal, Rapport nr. 5-1986.

2. Forseth U, Petersen SØ. Vedvarende variasjoner? Bruk av sykehus i Nord-Trøndelag 1979-84. Trondheim: Norsk institutt for sykehusforskning, Rapport nr. 2-1986.

3. Pedersen PB, Petersen SØ. Sykehusinnleggelser og sykehuskostnader i Namdalen. Trondheim: SINTEF, NIS, STF 81 A93015, 1993.

4. Petersen SØ, Kalseth J. Innherred sykehus. aktiviteter og kostnader 1992-1993. Trondheim: SINTEF, NIS, STF 81 A94096, 1994.

5. Kalseth B. Variasjoner i sykehusforbruket i Nord-Trøndelag. Rapportutkast STF 81 A94025.

6. Fylkesplan for Nord-Trøndelag 1993. Statistikk. Steinkjer: Fylkesrådmannen i Nord-Trøndelag, 1993.

7. Fylkesplan for Nord-Trøndelag 1992-95. Steinkjer: Fylkesrådmannen i Nord-Trøndelag, 1991.

8. Sammenligningstall for kommunene 1995, Nord-Trøndelag, Sør-Trøndelag, Møre og Romsdal. Oslo: Sosialog helsedepartementet, Hefte I-0821/2B, 1995.

9. Aase A. Helsetilstand. I: Nilsen S, hovedredaktør. Nasjonalatlas for Norge: Helse. Hønefoss: Statens Kartverk, 1996.

10. Folkehelserapporten. Helseminister Gudmund Hernes' redegjørelse om folkehelsen i Stortinget 30. april 1996. Oslo: Sosial- og helsedepartementet, 1996.

11. Fretland S, Krüger Ø, Graven T, Hegbom K. Regional differences in hospital admission rates for suspected and verified myocardial infarction in Nord-Trøndelag county, Norway. Scand J Prim Health Care 1997; 15: 210-13.

12. Fretland S. Helse i Nord-Trøndelag - en sammenligning mellom Namdal og Innherred. Verdal: Samfunnsmedisinsk forskningssenter, Folkehelsa Verdal, 1998.

13. Fretland S, Krüger Ø. Forskjeller i diagnosekriterier for akutt hjerteinfarkt ved norske sykehus. Tidsskr Nor Lageforen 1997; 117: 817-9. 